\title{
Nursing work at night in palliative oncology care ${ }^{1}$
}

\author{
Marcelle Miranda da Silva ${ }^{2}$ \\ Marleá Chagas Moreira ${ }^{3}$ \\ Joséte Luzia Leite ${ }^{4}$ \\ Alacoque Lorenzini Erdmann ${ }^{5}$
}

Objective: to understand the meaning baccalaureate nurses and nursing technicians attribute to night work in the context of clinical palliative oncology nursing care services, as well as how nursing works to attend to clients and caregivers' needs in this period. Method: in this exploratory and qualitative study, grounded theory was used. Seven nurses and four nursing technicians were interviewed, who composed two sample groups. Nine categories were produced and, in their comparative content analysis, a knowledge emphasis was evidenced with implications for nighttime nursing work. In this study, these aspects were discussed in two of the categories, which are: to describe care practice in order to understand nursing care management and to point out the difficulties in care practice and nursing care management. Results: The results evidence the complexity in the nighttime care context, considering the clients' clinical conditions and clients and caregivers' psychological demands, mainly because of the threat of death. Conclusion: The team attempts to respond to these needs through communication, but reveals a lack of assistential services and an overload. Interdisciplinarity is a palliative care premise, favoring holistic care delivery, and cannot be neglected at, which requires attention and investment to develop better practices.

Descriptors: Hospice Care; Oncologic Nursing; Night Work.

\footnotetext{
${ }^{1}$ Paper extracted from Doctoral Dissertation "O gerenciamento do cuidado de enfermagem na atenção paliativa oncológica", presented to Escola de Enfermagem Anna Nery, Universidade Federal do Rio de Janeiro, Rio de Janeiro, RJ, Brazil.

2 PhD, Adjunct Professor, Escola de Enfermagem Anna Nery, Universidade Federal do Rio de Janeiro, Rio de Janeiro, RJ, Brazil.

${ }^{3}$ PhD, Associate Professor, Escola de Enfermagem Anna Nery, Universidade Federal do Rio de Janeiro, Rio de Janeiro, RJ, Brazil.

${ }^{4}$ PhD, Full Professor, Universidade do Estado do Rio de Janeiro, Rio de Janeiro, RJ, Brazil.

${ }^{5}$ PhD, Full Professor, Departamento de Enfermagem, Universidade Federal de Santa Catarina, Florianópolis, SC, Brazil.
} 


\section{Introduction}

Palliative care comprises a set of active and comprehensive care actions aimed at maintaining the comfort and quality of life of patients affected by lifethreatening chronic illnesses like cancer. These actions are based on the interdisciplinary approach, so as to attend to the physical, social, psychological and spiritual needs of patients and their relatives ${ }^{(1)}$.

In the global context, the World Health Organization (WHO) has addressed this care mode, which requires investments in Brazil in view of the epidemiological representativeness of cancer and the important demographic transition population aging has brought about. In accordance with international policies, this care mode is secured in Brazilian health care through the National Cancer Care Policy, and is part of the Ministry of Health's research priorities ${ }^{(2-3)}$.

In cancer management, the palliative care phase is characterized by clients' emotional and clinical instability, with exacerbated systems that worsen their quality of life and can represent the complex process of dying and death. In this phase, in many situations, clients need hospitalization, and the hospital can end up being the place of death, although it often may not be the most appropriate place for end of life care, in defense of home care as the main care modality.

In Brazil, end-of-life care mostly takes place in hospital, to the detriment of the limited number of health teams trained for care delivery to these clients in the primary care context. Although this care level comprises specific home care programs, in accordance with the Unified Health System (SUS) management model, data for 2010 published by DataSUS show that the hospital is the main place of death, corresponding to $80 \%$ of deaths due to cancer $^{(4)}$.

During hospitalization, the nursing workforce is the most involved in care delivery to clients and their caregivers, considering its 24-hour presence(5). In palliative care, the night shift can represent the proximity of death, triggering fear and psychological and spiritual disorders in patients. In many hospitals, however, health team members are absent from the nursing services during this shift. Nevertheless, attending to these needs, which contribute to the worsening of the client's clinical condition, requires immediate actions, as these care spheres are fundamental in this phase of human experience.

In view of this true need, the study was structured based on the following hypothesis: the absence of other health team professionals from the clinical palliative oncology nursing care services during the night shift deprives the care mode from its characteristics. These needs should be attended to immediately, and cannot await the shift transfer the next morning. Hence, in view of the urgency, nursing attempts to respond as possible, but experiences practical difficulties related to the lack of assistential services(6). Thus, the study was guided by the following questions: what is the meaning baccalaureate nurses and nursing technicians attribute to night work in the context of clinical palliative oncology nursing services? How do these professionals develop the nighttime work in the absence of other health team professionals in this context?

The study was aimed at understanding the meaning baccalaureate nurses and nursing technicians attribute to night work in the context of clinical palliative oncology nursing services, as well as how nursing works to respond to clients and caregivers' needs during this period. It is justified by the need to provoke reflections on the actual needs of nighttime work at the clinical nursing services, taking into account the care mode in palliative oncology care, based on the premises of integrality and interdisciplinarity, besides contributing to the organization of healthy work spaces for nursing in this context.

\section{Method}

This exploratory study with a qualitative approach is part of the doctoral dissertation entitled "Nursing care management in palliative oncology care". Exploratory research is aimed at getting to know reality as it presents itself, through its delimitation, bibliographic survey, interviews with people who have gone or are going through the practical experiences, and the reading and analysis of documents. And the choice of the type of approach derives from the production of results that cannot be achieved through quantifiable procedures ${ }^{(7-8)}$.

The methodological reference framework of Grounded Theory (GT) was used. Through this method, the intent is to support concepts on data extracted from realities, involving subjects in constant interactions ${ }^{(8)}$.

In GT, data collection and analysis take place simultaneously, characterizing comparative analysis. The analysis is structured based on coding processes, the first of which refers to open coding, looking for preliminary codes based on a line-by-line analysis of gross data, which will serve as the construction blocks for the categories and subcategories; the second refers 
to axial coding, when the categories and subcategories are defined and grouped; and, finally, selective coding is undertaken, when the elements of the paradigmatic model are used to interconnect the categories and reveal the central study phenomenon ${ }^{(8)}$.

The paradigmatic model attempts to integrate structure and process. The coded data and ordered and interconnected, taking into account the structural conditions and the process, related to actions and interactions in time, space, with people, organizations and societies, in response to the problems. Structural conditions refer to the causal conditions, context and intervening conditions, which respond to the questions: why, where, how and when. The process concentrates the action-interaction strategies and consequences. The strategies can be individual or collective and mean actions towards the problems. And the consequences represent achievable results or expectations ${ }^{(8)}$.

The data were collected at the clinical nursing services of Hospital do Câncer IV (HC-IV), which is the unit specialized in palliative oncology care of the Instituto Nacional de Câncer (INCA), located in the city of Rio de Janeiro, Brazil. The hospital consists of four nursing services, with 14 beds each. During night shifts, weekends and holidays, the nursing team comprises two baccalaureate nurses, each responsible for two floors, and three to four nursing technicians per floor. Both categories work 40 hours per week. On workdays, a hired nurse is also present on each floor.

Study participants were 11 subjects, in two sample groups, one with seven baccalaureate nurses and the other with four nursing technicians. Data collection was interrupted with this number of subjects due to saturation, when the testimonies no longer brought new relevant information for the research. In addition, the contribution of the comparative method of GT to theoretical saturation is highlighted.

The subjects complied with the following inclusion criteria: being a nursing professional formally employed at the institution and having worked at the clinical nursing service for at least six months. During data collection, one baccalaureate nurse did not comply with the experience criterion, another nurse who worked as a hired nurse had been allocated to another sector, and five nursing technicians did not accept to participate in the study.

Working night shifts only was not set as an inclusion criterion because this study is part of a doctoral research without this focus. Nevertheless, the particularity of nighttime work stood out as one of the bottlenecks for nursing care management. It should be highlighted that all subjects, independently of the preset shift scale, work or have worked at night, whether to complement their hour load or as a result of shift changes between peers.

All participants signed the Informed Consent Term, in compliance with the ethical aspects of National Health Council Resolution 196/96. The research received approval from the INCA Research Ethics Committee, registered under opinion 45/10.

Data were collected between October 2010 and February 2011. The technique used was the semistructured interview, based on a script. In this study, the following questions were highlighted: what is the meaning you attribute to night work in the context of clinical palliative oncology nursing wards? How do you practice your work in that period to respond to clients and caregivers' needs?

Each interview was digitally recorded and fully transcribed. This phase was developed for each interview, in a cyclical and dynamic process between data collection and analysis, with constant comparison and interaction between the gross data and the codes produced.

Nine categories were identified, mainly guided by the baccalaureate nurses' testimonies, which were: understanding nursing care management; describing practice to understand nursing care management; dialoging with caregivers; attending to the needs of hospitalized clients; working as a team; drawing the care flow at the hospitalization unit; appointing practical and nursing care management difficulties; acknowledging the constituent elements of nursing care management practice; and manifesting the baccalaureate nurse/ nursing technician as a being who takes and needs care.

In the content analysis of these categories, and in the interconnection process to reveal the central phenomenon, based on the comparative analysis, a knowledge emphasis was evidenced with implications for nighttime nursing work. These aspects, who represent causal and intervening conditions, stand out in the theoretical model produced and were discussed in the present study with a focus on two categories: describing practice to understand nursing care management, and appointing practical and nursing care management difficulties.

The discussion of the data was based on the contributions of Edgar Morin's science of complexity, palliative care premises, and authors who discuss the theme in nursing knowledge. 


\section{Results}

The eleven study subject' mean experience time at the clinical wards was seven years, ranging between one and sixteen years, which demonstrates the group's great practical experience.

The aspects that join the main answers related to the research questions were processed in two categories, which are part of the theoretical model constructed in the thesis, based on the dialogical principle of complexity.

The theoretical model is a substantive theory, representing a given reality, demanding additional research for its general application, and comprises: the baccalaureate nurses manage nursing care in palliative oncology care in response to the needs of hospitalized patients and their caregivers. They value the development of skills to reach the care objectives, so as to compose a new order in the scenario, in view of the dialogic relations between order and disorder, life and death, and to overcome the difficulties related to personal, collective and institutional limits.

Picturing the reality under analysis, the institutional limits strongly evidence the problems of night work related to the absence of other health team members and insufficient human resources in nursing. In these conditions, the imminence of death and clients' psychological and spiritual disorders can be more difficult for nursing to manage, causing an overload and contributing to the expression of individual and collective limits in daily coping with suffering and pain.

In the attempt to respond to clients and family members' demands, many nursing professionals need to develop skills, particularly for communication. The reference to the dialogic relation between order and disorder in care management is directly influenced by the strong threat of death, somatized by clients' nighttime dread. Thus, the complexity of the context is valued, as pictured in the central phenomenon: managing palliative oncology nursing care in response to the needs of hospitalized patients and their caregivers, valuing care delivery and its complexity.

In the category Describing practice to understand nursing care management, identified as a causal condition, the baccalaureate nurses understand professional practice based on the description of what is done, including the subcategory Reporting on baccalaureate nurses' work process in daytime and nighttime services. In the category Appointing practical and nursing care management difficulties, identified as an intervenient condition, the relevant subcategories for the study include: Exercising different actions in the absence of other interdisciplinary team members; Highlighting the shortage of nursing human resources as a problem; and Experiencing the physical and psychosocial changes clients and caregivers feel in the short, medium and long term.

The nursing team highlights the clients' profile as a factor that enhances the probability of problems at night, and which would be managed better if other health team professionals cooperated. This problem is described in the following testimony: at night, the psychological demand is very high, whether involving patients or relatives, and we don't have the psychologist then. So, I manage care not in the way I find ideal, but as I am able to, so as not to leave the patient's needs unattended (Nurse 01).

The nighttime alone contributes to exacerbate the fear of death, due to the nightly dread many clients feel, which can contribute to somatize physical symptoms. The combination of these factors triggers negative feelings in caregivers, who can experience fear, anxiety, powerlessness and anticipated mourning due to the death of a loved one. During the day, when relatives need psychological support, the psychologist is immediately informed, and the nurse is always making this link, contacting other professionals as demanded, but at night that is not possible, which makes things difficult. In this case, we are responsible and need to be the psychologists, social workers, so it gets really hard. And, in fact, at night, everything happens (Nurse 01).

In that sense, the nursing team, particularly the baccalaureate nurse, needs to perform different actions in nighttime work to respond to the needs of clients and their caregivers. And the nurse attempts to act in the best possible way, like, for example, if the relative is emotionally disrupted because of the loss, because of the anticipated mourning experience, but she won't be as well equipped as the psychologist, who was prepared for this (Nurse 07).

The need to rapidly intervene in order to manage multiple problems that involve human beings and their finiteness contributes to nursing professionals' physical and emotional overload. In their testimonies, these professionals express the importance of teamwork, so that care and organizational demands can be attended to in the best possible way. At night, the cooperative relation in the team is strengthened, as the number of nursing staff is smaller than in the daytime period. In nighttime work, one nurse has to manage two clinical nursing service floor. So, it's even difficult for us to better manage this care. Therefore, I need to trust the technical team, because we are neither omnipresent nor omniscient, but we need to be, and that will happen through teamwork. So, I need to trust them (Nurse 01). 
The small number of baccalaureate nurses at night can contribute to a possible negative impact on nursing care quality. In their testimonies, the nursing technicians highlighted that: in the night shift, we feel that the nurse needs to be present, as well as the other team professionals. When we're having a complicated situation, sometimes we need to call the physician, and the nurse may be on another floor. But that happens because of the lack of employees. I think other professionals would be necessary at night, like a social workers and a psychologist, for support, because nursing ends up performing these functions in care delivery, like when the patient dies for example (Nursing technician 09).

At night, the physician is present on demand. In other words, in case of a problem, nursing telephones the physician, who is on duty in the emergency sector. This condition was also identified as a problem that interferes in the dynamics of nursing work. It would be very good to have a physician just for the sector because, when there's a problem, no matter how much he tries to come quickly, we have to wait a bit, keep on calling, and that makes the family feel anxious and transmit this to the team, which ends up absorbing the emotional overload. When death happens and the family gets anxious, nursing has a lot to do, like preparing the body, supporting the family and attempting to control the situation. It would be good to have someone on call at night to do that with us (Nursing technician 11).

The problems threatening the client's life need to receive immediate intervention, involving interdisciplinary team professionals, with a view to comprehensive care delivery that extends to caregivers. In the context of their management actions, baccalaureate nurses act as information articulators, negotiators and mediators, favoring teamwork. Nevertheless, you can only count on the nursing team at night, and there's no way to contact the other health team members, which makes articulation difficult (Nurse 02).

On some occasions, these care demands cannot await the shift transfer, and it is the nursing team that attempts to collaborate so that everything works out (Nursing technician 10).

\section{Discussion}

The success of palliative care, with a view to comfort, quality of life and human dignity in the finite process, derives from the interdisciplinary team's efforts and combined knowledge and actions. In nighttime work at the clinical ward under investigation, however, the reality is deprived of the characteristics of this care mode, as nursing acts in isolation, without a network of collaborators, suffering due to the physical and emotional overload.

Interdisciplinarity is the starting point for holistic palliative care delivery. This refers to the interaction between two or more disciplines, in the attempt to overcome the fragmentation of knowledge/action, which in the health area refers to the fragmentation of the human being, as well as to qualify care delivery ${ }^{(9)}$. In the field of complexity, interdisciplinarity attempts to separate and associate, communicate scientific knowledge and root the anthropological sphere in the biological sphere at the same time, through contextualization, moving beyond the physical aspects of the disease, against the emphasis on the biomedical/Cartesian model(10).

The great work demand, related to the complexity in the palliative care context, in view of clients' clinical instability and the possibility of death, which can increase at night, evidencing human problems that affect multiple dimensions, demands that nursing teamwork takes place based on cooperation, surveillance and dynamics, when performing different actions without the presence of other health team members. This demand level, however, in combination with the shortage of nursing human resources at night, can comprise these professionals' health and care quality, as clients and caregivers face great psycho-emotional demands, with limited tasks that require that nurses forward these care actions to equipped team professionals.

As regards the human resource deficit, it should be highlighted that, in view of the nursing staff dimensioning criteria in Federal Nursing Council Resolution $293 / 2004^{(11)}$, it is difficult to frame palliative care demands, showing the need for reconsiderations that value characteristics of dependence and these clients and their family members' needs. Various factors contribute to the logic of nursing human resource dimensioning in hospitals, including capitalism, aimed at productivity and lower cost, against the guiding principles of public policies and some care models ${ }^{(12)}$.

When attempting to respond to clients and caregivers' needs, the first skill nursing professionals need to develop is communication. All health professionals need to develop communication, as one of the pillars of palliative care, independently of their educational background(13). Besides communication, however, palliative care premises include interdisciplinarity, which cannot be neglected at night in the wide range of scenarios in which people experience the end of life.

Negative feelings and concerns can affect palliative care clients, including fear, death, suffering, solitude and 
the family relations left behind ${ }^{(13)}$. During hospitalization, in a depersonalized environment, and mostly in worse clinical conditions, everything can get worse, especially at night, triggering nighttime dread, which demands a type of intervention that involves communication and active listening and demands the time and dedication of the nurses, who are overloaded though.

As a strategy to cope with the difficulties of nighttime nursing practice, the baccalaureate nurses evidenced the necessary trust relation and team spirit. In the management dimension, this strategy remits to participatory leadership, which remits to a contemporaneous view of leadership as a form of work that values team members' experiences and potential resources, demanding relational competencies as well as shared and complementary actions among peers, who support decision making during shifts when their heads are not present ${ }^{(14-15)}$.

Hence, participatory leadership is an important strategy, mainly at night, in view of the integration needed for nursing care management. Differently from some realities presented in research(6,15), however, which indicate the tranquility of the nighttime period as a factor that facilitates care actions and planning, with less people circulating, in palliative care, the possible changes in clients' clinical conditions and their psychoemotional disorders were appointed as factors that hamper these actions and demand further support from care services.

Participatory leadership is capable of transforming decision making in collective conceptions, which strengthen the group. In view of the nursing workforce's practically isolated action at night, however, it is evidenced, particularly in the reality studied, that the shortage of baccalaureate nurses can compromise this practice, considering that nursing technicians' testimonies express the need for baccalaureate nurses' full-time presence.

Palliative care practice faces various challenges and still lacks investments, as many people still do not receive appropriate care at the end of life ${ }^{(16)}$. Its basic principle has evolved through political and bioethical advances though, as a fundamental need that can represent a lower cost. All health professionals should be responsible for this care mode, as well as clients and caregivers. A sole professional cannot attend to all needs in these circumstances of life, as care is continuous and death presents itself in a constant dialogical relation between certainty and uncertainty, which can happen at any time, including at night.

\section{Final Considerations}

Based on the selected categories, that is, Describing practice to understand nursing care management and Appointing practical and nursing care management difficulties, the results indicated that the context of clinical palliative oncology nursing care services is complex, especially during the night shift, considering the instability of clients' clinical conditions and clients and caregivers' great psychological demand, mainly due to the threat of death.

The nursing team attempts to respond to these needs, which requires communication and active listening skills. Nevertheless, the lack of assistential services and the physical and psychological overload is evidenced. Work is developed based on the valuation of nursing team members' potential resources, the relationship of trust and relational competency.

Palliative care is based on the premises of integrality and interdisciplinarity, which cannot be neglected in the nighttime period, within the wide range of scenarios in which people experience the end of life. Based on this research, it could be evidenced that the night shift in palliative oncology care differs from other contexts, which appoint tranquility as a facilitator of care actions and planning.

In general, this care mode requires managers' attention and investments to provide appropriate resources, with a view to better palliative care practices. This is a challenge for the health system. It is important to discuss and disseminate the theme, as a focus of further scientific research in different health knowledge areas.

\section{References}

1. World Health Organizations. National cancer control programmes: policies and managerial guidelines. 2nd ed. Genebra: WHO; 2002.

2. Portaria no $2.439 / \mathrm{GM}$ de 08 de dezembro de 2005 (BR). Institui a Política Nacional de Atenção Oncológica. Brasília (DF): Diário Oficial da União; 9 Dez 2005.

3. Ministério da Saúde (BR). Agenda nacional de prioridades de pesquisa em saúde. $2^{a}$ ed. Brasília (DF): Editora do Ministério da Saúde; 2008. 68 p.

4. Ministério da Saúde (BR). Departamento de Análise de Situação de Saúde. Sistema de informação sobre mortalidade. [internet]. 2010 [acesso 29 ago 2012]. Disponível em:

http://tabnet.datasus.gov.br/cgi/tabcgi.exe?sim/cnv/ obt10uf.def 
5. Pimenta CAM. Palliative care: a new specialty in profession of nursing? Acta Paul Enferm. 2010 MaioJun;23(3): xi-x

6. Silva RM, Beck CLC, Guido LA, Lautert L, Tavares JP, Prestes FC, et al. Night shift pros and cons in nursing: qualitative study. Online braz. j. nurs. [internet]. 2009 Ago [acesso 05 nov 2011];8(2). Disponível em: http:// www.objnursing.uff.br/index.php/nursing/article/ view/j.1676-4285.2009.2346

7. Oliveira MM. Como fazer pesquisa qualitativa. $3^{a}$. ed. Rio de Janeiro (RJ): Vozes; 2010. 232 p.

8. Strauss A, Corbin J. Pesquisa qualitativa: técnicas e procedimentos para o desenvolvimento de teoria fundamentada. 2a. ed. Porto Alegre (RS): Artmed; 2008. 288 p.

9. Benito GAV, Finato PC. Competências gerenciais na formação do enfermeiro: análise documental de um projeto pedagógico de curso. Rev Eletrônica Enferm. [internet] 2010, jan-mar. [acesso: 08 jul 2011];12(1):140-9. Disponível em: http://www.fen. ufg.br/revista/v12/n1/v12n1a17.htm

10. Morin E. Ciência com consciência. $13^{a}$ ed. Rio de Janeiro (RJ): Bertrand Brasil; 2010. 350 p.

11. Conselho Federal de Enfermagem (BR). Resolução no 293/2004. Fixa e estabelece parâmetros para o dimensionamento do quadro de profissionais de enfermagem nas unidades assistenciais das instituições de saúde e assemelhados [internet]. 2004 [acesso: 29 ago. 2012] Disponível em: http://www.saude.mg.gov.br/ atos_normativos/legislacao-sanitaria/estabelecimentosde-saude/exercicio-profissional/res_293.pdf

12. Vituri DW, Lima SM, Kuwabara CCT, Gil RB, Évora YDM. Dimensionamento de enfermagem hospitalar: modelo OPAS/OMS. Texto Contexto Enferm 2011 JulSet;20(3):547-56.

13. Araújo MMT, Silva MJP. Estratégias de comunicação utilizadas por profissionais de saúde na atenção à pacientes sob cuidados paliativos. Rev Esc Enferm USP. 2012 Jun;46(3):626-32.

14. Marquis $B$, Huston $C$. Administração e liderança em enfermagem: teoria e aplicação. $6^{a}$ ed. Porto Alegre: Artes Médicas; 2010. 671 p.

15. Costa DG, Dall'Agnol CM. Participative leadership in the management process of nightshift nursing. Rev. Latino-Am. Enfermagem. [internet] 2011 nov-dez. [acesso: 02 fev 2012]; 19(6):1306-13. Disponível em: http://www.scielo.br/pdf/rlae/v19n6/05.pdf
16. Lima RAG. Palliative care: challenges for the health systems. Rev. Latino-Am. Enfermagem. [internet]. 2011 mar-abr. [acesso: 02 fev 2012];19(2):227-8. Disponível em: http://www.scielo.br/pdf/rlae/v19n2/pt_01.pdf 